

\section{La carga de la prueba en el proceso civil: una evolución desde la igualdad formal de las partes hacia una igualdad material de las mismas*}

\section{Andrés Bordalí-Salamanca**}

\section{Resumen}

El presente trabajo tiene por finalidad analizar cómo ha evolucionado el proceso civil de tipo continental a la luz del principio de igualdad, desde una igualdad formal a una material. Esa evolución se refleja en una serie de reformas legislativas en la mayoría de los países de tradición continental, que buscan igualar la posición de las partes en el proceso. Dentro de las últimas medidas correctoras están aquellas que buscan alterar la clásica y liberal regla del onus probandi, que se entiende, desfavorece en muchos casos la situación del demandante débil o de quien no dispone de las fuentes de prueba. Se estudia, por tanto, la denominada carga dinámica de la prueba, las presunciones a favor de los demandantes y una medida que busca alterar las reglas sobre la carga de la prueba, pero también disminuir el grado de certeza que la prueba le arroja al juez para dar por establecidos los hechos constitutivos de la pretensión, como es la que existe en algunas hipótesis del derecho antidiscriminación y del proceso laboral. Palabras clave: carga de la prueba; facilidad probatoria; presunciones.

\section{The burden of proof in civil proceedings: an evolution from the formal equality of the parties to their material equality}

\section{Abstract}

The purpose of this paper is to analyze how the continental-type civil process has evolved, in light of the principle of equality; from formal to material equality. These developments are reflected in a series of legislative reforms in most countries that have a continental tradition, which seek to equalize the position of the parties in the process. The latest corrective measures include those that seek to alter the classic and liberal rule of onus probandi, which is understood, in many cases, to be detrimental to the situation of the weak plaintiff or the person who does not have sources of proof. It therefore studies the so-called dynamic burden of proof; the presumptions in favor of the plaintiffs and a measure that seeks to alter the rules on the burden of proof, but also to reduce the degree of certainty that the evidence provides to the judge in order to establish the facts constituting the claim, as is the case in some hypotheses of anti-discrimination law and the labor process.

Key words: burden of proof; ease of proof; presumptions.

\section{O ônus da prova no processo civil: Uma evolução da igualdade formal das partes para uma igualdade material da mesma}

\section{Resumo}

0 presente trabalho tem a finalidade de analisar a evolução do processo civil continental, à luz do princípio de igualdade; indo de uma igualdade formal a uma igualdade material. Essa evolução se reflete numa série de reformas legislativas na maioria dos países de tradição continental, que procuram igualar a posição das partes no processo. Dentro das últimas medidas corretivas estão aquelas que procuram alterar a clássica e liberal regra do onus probandi, que em muitos casos não favorece a situação do demandante mais fraco ou daquele que não dispõe das fontes de prova. Estuda-se, portanto a denominada carga probatória dinâmica da prova; as presunções favoráveis aos demandantes e uma medida que altere as regras sobre o ônus da prova, mas também que diminua o grau de incerteza que a prova proporciona ao juiz para determinar como estabelecidos os fatos constitucionais da pretensão, como acontece em algumas hipóteses do direito da antidiscriminação e do processo laboral. Palavras-chave: ônus da prova; facilidade probatória; presunções.

* $\quad$ Artículo de reflexión.

** Profesor Titular de Derecho, Universidad Austral de Chile,Chile. Abogado, Doctor en Derecho, investigador en Derecho Procesal. Correo electrónico: abordali@uach.cl ORCID: 0000-0002-5126-8037

Cómo citar este artículo: Bordalí Salamanca, A. (2020). La carga de la prueba en el proceso civil: una evolución desde la igualdad formal de las partes hacia una igualdad material de las mismas. Estudios de Derecho, 77 (170), $201-225$ 


\section{La carga de la prueba en el proceso civil: una evolución desde la igualdad formal de las partes hacia una igualdad material de las mismas}

\section{Introducción}

La ideología que informa el derecho moderno codificado a comienzos del siglo XIX es común para todo el ordenamiento jurídico. De este modo, la idea de un derecho general y abstracto, del sujeto abstracto de derecho y de la igualdad de todas las personas ante la ley, también tuvo su correlato en el ámbito del proceso judicial.

Ante el Estado-Juez, la modernidad concibió dos sujetos privados que se encuentran en plena igualdad entre ellos. Me refiero a las partes procesales, estas en una contienda judicial son iguales ante la ley y tienen absoluta igualdad en el uso de las armas procesales.

La abstracción del derecho y en concreto de los sujetos de derecho corresponde a un modo en que el derecho posrevolución francesa intenta frenar la violencia y la venganza entre los individuos. No importa la situación material en que se encuentran las personas tras el ropaje de sujeto de derecho o, también, de parte procesal. Da lo mismo que sea hombre o mujer, rico o pobre, terrateniente o jornalero; la ley asume que esos sujetos son iguales ante la ley y, si existen diferencias, estas son absolutamente irrelevantes en esta construcción de la imagen del sujeto.

Los códigos legales decimonónicos, sustantivos o procesales, niegan la relevancia del sujeto individual y su existencia material. La consideración material y social del hombre por el derecho, en la ideología de la modernidad, comportaría abrir nuevamente las puertas al mundo del Medioevo y daría lugar a la violencia desatada entre unos sujetos que detentan el poder y los sujetos que forman parte de los distintos estamentos sociales y entre poderes y estamentos y personas entre sí.

Así como el Estado nación pretendió ser un mecanismo de dominación y control de la guerra de todos contra todos, el sujeto abstracto de derecho que se encuentra en una situación de igualdad (formal), también es un mecanismo ideado a inicios del siglo XIX en Francia para pacificar y aminorar el conflicto social. Es desde luego, por otra parte, un instrumento ideológico y político que pretende 
facilitar los negocios de un sector de la sociedad de ese entonces, como lo era la burguesía. Asimismo, es una ficción que intenta simplificar la realidad social, que por definición es compleja, con fines de control social y económico por parte de la burguesía dominante.

Esta imagen del hombre y de la sociedad expresada en los códigos decimonónicos burgueses; esta ficción que intentaba simplificar la realidad social, comienza a desvanecerse apenas aparecen las primeras movilizaciones de masas y una leve democratización del poder a fines del siglo XIX. Ese desvanecimiento del sujeto abstracto de derecho y de la igualdad formal, da paso a la consideración del sujeto concreto material que se encuentra tras las normas legales.

Es que en realidad el proyecto moderno se trataba simplemente de una ficción que se oponía a la realidad social y a las desigualdades que se esconden tras el andamiaje jurídico y, por lo tanto, estaba condenado a caer o al menos a ser modificado en algún momento.

Dejando de lado al proceso penal en el que puede entenderse que, salvo en períodos de la República en Roma y en algunos momentos en el derecho inglés, nunca ha sido un proceso entre partes iguales; formal o materialmente hablando, el proceso civil siempre ha sido asumido como un proceso entre iguales. Sin embargo, ese proceso civil formalmente igualitario comienza a cambiar desde fines del siglo XIX. Y un siglo más adelante, las diferentes legislaciones han introducido importantes modificaciones para igualar la posición de los sujetos contendientes frente a la prueba que se rinde en el proceso.

En el desarrollo del presente trabajo analizaré cómo evolucionó el proceso civil de tradición continental durante el siglo XX. Esa evolución la consignaré como un paso del proceso civil del laissez faire a uno social o, si se quiere, propio del Estado benefactor o interventor. Luego de dejar explicitada en qué consistió tal evolución, analizaré en particular las propuestas que en los últimos años se han realizado en materia probatoria, que tienen entre sus finalidades fortalecer la posición de los sujetos más débiles de la relación jurídica procesal o de aquellos que tienen dificultades para acceder a las fuentes de prueba. Analizaré al proceso civil de un modo amplio, pues consideraré dentro de él al proceso laboral.

\section{Del proceso civil del laissez faire al proceso civil del Estado social}

El proceso civil de las sociedades liberales siempre ha funcionado de un modo tal para que exista una igualdad entre las partes de la contienda. Pero me refiero a una igualdad formal, lo que equivale decir a que se presume que las partes están en una situación de igualdad. 
En un proceso de un Estado de ideología liberal o del laissez faire,

Las partes son tratadas "abstractamente", separadas de sus diferencias personales (substantivas) y como portadores equivalentes de derechos procesales. ... Como la estatua de la diosa con las balanzas que personifica la justicia, el adjudicador en el modelo puro está ciego. Las desigualdades que emanen de fuentes diferentes a las reglas procesales "abstractas", no entran en el equilibrio. (Damaska, 2000, pp. 185-186)

Sin embargo, a fines del siglo XIX se observa una paulatina modificación del proceso civil en lo referido al rol del juez y la situación de las partes procesales, pues las diferencias económicas y sociales de los litigantes por primera vez entran en la consideración del legislador y del juez.

A fines del siglo XIX se produce un cambio sustancial en la relación jurídica procesal de carácter civil. Ello sucede con la Ordenanza Procesal austriaca de 1895. La Ordenanza, obra principal del Ministro de Justicia Franz Klein, fue una reacción política al modelo de Estado y al proceso civil del liberalismo europeo del siglo XIX, que establece una relación de absoluta igualdad formal de las partes procesales y una situación de pasividad del juez quien se desentiende del andar del proceso, pues este pertenece a las partes. Nace así en el año 1895 un proceso civil de carácter social o público.

La idea central de Klein era hacer del proceso civil un proceso dirigido activamente por el juez con el fin de resolver lo antes posible el conflicto que involucraba a dos partes. Esa rapidez en el término del juicio beneficiaba al conjunto entero de la sociedad.

La propuesta de Klein era de orientación socialista o socialdemócrata. Es que en esta materia el jurista vienés tuvo influencia de Anton Menger, uno de los cultivadores del denominado socialismo jurídico. Menger había escrito un libro a fines del siglo XIX denominado: El derecho civil y el proletariado, donde afirmaba que las instituciones judiciales son siempre, y tanto más cuanto más complejas y costosas, un instrumento de un ulterior poder para quien es más rico y poderoso, lo que era una constatación habitual en toda la literatura socialista de fines del siglo XIX. Por este motivo, Menger reclamaba para el juez civil mayores poderes en el proceso, para así poder suplir las deficiencias en la conducta procesal de la parte más pobre (Tarello, 1989).

Klein, en la Ordenanza, va más allá de la particular situación de las partes en el proceso y es quizás el primero que visualiza en el proceso civil un fenómeno social de masas. Por ello, el proceso civil debía ser regulado cual instituto de bienestar social. El pensamiento de Klein en la materia se basaba en dos grandes postulados, como lo resume Cipriani (1997): a) Las controversias individuales son males sociales que se relacionan con pérdida de tiempo, derroche de dinero, indisponibilidad infructuosa de bienes patrimoniales, fomento del odio y de la 
ira entre las partes litigantes y otro tipo de pasiones fatales para la convivencia social; b) El proceso, en la medida que bloquea bienes en espera de la decisión final, incide sobre la economía nacional. Por ello la sociedad estaría interesada en sanar lo más rápido posible este tipo de heridas. Existe un claro análisis de economía institucional en este análisis del proceso civil.

Luego, el proceso ideado por Klein en Austria, tuvo una fértil acogida en Italia a través de Giuseppe Chiovenda y desde ahí pasó a los países latinoamericanos. Chiovenda relacionó la oralidad y fuerte dirección de los procesos por el juez, como Menger, con la rapidez de los mismos. Esos fuertes poderes del juez y la rapidez en el andar del proceso oral y de la solución del conflicto eran necesarios para ayudar a la parte más pobre.

El otorgamiento de mayores poderes al juez civil se justificaba, para autores como Menger y Chiovenda, con la idea de amparar a la parte procesal más pobre e indefensa. Para Klein esos mayores poderes del juez se sustentaban por el mayor beneficio social en la pronta resolución del asunto.

Durante todo el siglo XX, la mayoría de los países regularon el proceso civil de un modo tal que se considerara la posición material de las partes en el proceso. La parte débil sería asistida de dos maneras distintas durante fines del siglo XIX y comienzos del siglo XX: en primer lugar, con un juez dotado de fuertes poderes para llevar adelante el proceso con máxima prontitud y con poderes para participar en la introducción de pruebas. En segundo lugar, se convino en la necesidad de crear una judicatura y un proceso especial para las relaciones jurídicas del trabajo, para tutelar así de mejor modo los derechos e intereses del trabajador. Nace así una relación jurídica entre trabajador y empleador que ya no se rige por el derecho civil sino por el derecho laboral y, por otra parte, además, se crea un proceso laboral diferente al civil.

Durante el siglo XX, se concibe en la mayoría de los países de tradición jurídica continental, una judicatura y un proceso laborales especiales. Por un lado, se quería un juez especialista en Derecho Laboral, para así proteger de mejor modo al trabajador. Por otra parte, se crea un proceso laboral que está informado por principios que pretenden potenciar o favorecer la situación jurídica del trabajador, el que, obviamente, no se encuentra en una posición de igualdad frente al empleador. Asimismo, atendida las necesidades de los trabajadores, se intenta que ese proceso funcione de un modo más rápido que el proceso civil declarativo.

El siguiente paso que se dio en el desarrollo del siglo XX fue el deber del Estado de procurar a los pobres asistencia jurídica gratuita, lo que autores como Cappelletti y Garth (1996) sitúan en el centro y norte de Europa alrededor de 1920 (p. 25). Esta asistencia jurídica gratuita sin duda contribuyó a los fines de igualar la posición material de las partes en el proceso. 
Sin embargo, más allá de esos mayores poderes del juez civil, de un proceso laboral escindido del proceso civil y de la asistencia jurídica gratuita a los pobres, durante todo el siglo XX nunca se adoptaron medidas legislativas que tendieran a compensar, procesalmente hablando, la situación desigual de las partes en el proceso civil. Solo a finales del siglo XX el proceso civil comenzó a crear instituciones procesales que intentaban reconfigurar la posición de las partes en el proceso.

Los pasos legislativos en orden a intentar igualar la situación de las partes en la justicia civil han sido varios. En primer lugar, se debe mencionar la regulación de un proceso y un derecho sustantivo del consumo, otra escisión del Derecho Civil operada a fines del siglo XX. Muchas legislaciones adoptan un proceso colectivo de tutela de los consumidores, en el que se suele permitir la participación activa de asociaciones de consumidores y de grupos de consumidores, lo que permite unir capacidad económica y de acción frente a la empresa que vende productos o servicios. En este sentido, el proceso de consumo pretende potenciar a la parte demandante frente a la empresa demandada. Sin duda, el proceso colectivo de consumo tiene otro fin, como lo puede ser una utilización eficiente del sistema de justicia, concentrando en uno solo eventuales múltiples procedimientos individuales, aunque una idea de igualación del poder procesal de las partes debe ser destacada.

El derecho probatorio no se ha quedado atrás en esta evolución. Así, en materia de prueba de los hechos controvertidos en el proceso, muchas legislaciones en las últimas décadas también han introducido cambios a las reglas sobre la prueba, como lo es la alteración de las reglas relativas a la distribución de la carga probatoria, de modo tal que la incerteza sobre el acaecimiento de los hechos constitutivos de la pretensión, perjudique al demandado y no al demandante. La base de estas alteraciones a la tradicional carga de la prueba está en la significativa asimetría que puede existir entre las partes del proceso (González Coulon, 2013).

Dentro de esta alteración a las reglas tradicionales sobre la carga de la prueba, está lo que se denomina la carga dinámica de la prueba, de origen argentino, al menos con ese nombre, al decir de Ferrer (2019, p. 63). Esta medida permite al juez que conoce del proceso, en el caso en concreto, alterar la carga y ponerla sobre el sujeto que tiene más facilidad de acceso a la prueba o mayor información sobre la misma. La carga dinámica de la prueba, se ha sostenido por varios autores, es una constatación de la concepción publicista del proceso (González Coulon, 2013), ese proceso civil que asumen la mayoría de los Estados desde la Ordenanza Procesal austríaca de 1895.

En otros casos se opta por establecer presunciones, ya sea sobre hechos, la culpabilidad o responsabilidad del demandado. En otras situaciones se ha optado por rebajar o disminuir el grado de certeza que la prueba haya de suministrar al juez para tener por fijados los hechos constitutivos de la pretensión, situándolo 
en un nivel de probabilidad cualificada o preponderante, excluyendo así una idea de plena convicción subjetiva o más allá de toda duda razonable.

En ocasiones, se ha decidido combinar algunos de estos mecanismos, dando lugar a la inversión de la carga de la prueba si se aportan indicios que hagan plausible o sugieran la probabilidad de que hayan acontecido los hechos constitutivos en que se basa la pretensión.

Estas reformas legislativas, por regla general, buscan favorecer la parte más débil en el proceso. Por parte débil suele entenderse la parte que tiene menos recursos económicos. Pero en ocasiones la ley va en ayuda no solo de sujetos débiles en términos socioeconómicos, sino también de aquellos sujetos que carecen de la información o acceso a determinadas fuentes de prueba, o les es muy difícil obtenerlas, independientemente de su situación socioeconómica. Así, por ejemplo, si un empresario exitoso se opera en una clínica y resulta con daños producto de una mala praxis médica, la ley puede poner la carga de probar en cabeza del médico tratante o la clínica donde se realizó la intervención quirúrgica, pues generalmente toda la prueba estará en poder del médico que operó o de la clínica donde se realizó la intervención. Y esa alteración de la carga de la prueba se justifica no porque el paciente que sufre el daño sea un sujeto débil, sino porque no dispone de la prueba.

Estas reglas operan entonces cuando existen sujetos débiles y en aquellos casos de asimetrías relevantes de información entre las partes o una especial dificultad para una parte para obtener las pruebas en su favor (Corral, 2012).

Con lo dicho, debe destacarse que el proceso reúne en sí un plexo de valores, entre los que destacan, como primordial, la búsqueda de la verdad. Sin embargo, ese valor verdad que a mi modo de ver nunca debe dejarse de lado en la dinámica del proceso, debe conjugarse adecuadamente con otros valores en juego, como lo es el de igualdad entre las partes, el de economía procesal, entre otros. Asumo que no es tarea fácil ponderar adecuadamente dichos valores. Será tarea ineludible de los distintos legisladores lograr una adecuada armonización entre ellos ponderándolos adecuadamente.

\section{Las reglas sobre la carga de la prueba y las dificultades probatorias}

\subsection{Reglas sobre la carga de la prueba: de la regla tradicional a sus alteraciones}

Como señalaba en páginas precedentes, durante los siglos XIX y parte del XX no hubo manifestaciones legislativas y jurisprudenciales en torno a alterar la carga de la prueba u onus probandi en el proceso. Rigió y continúa rigiendo en muchos de los países de tradición continental una regla similar a la que existe en el ordena- 
miento jurídico chileno, que señala que "incumbe probar las obligaciones o su extinción, al que alega aquellas o éstas" (artículo 1698 del Código Civil). Se acostumbra denominar a esta forma de la carga probatoria, como carga subjetiva, que hace referencia al rol de las partes con respecto a aportar medios de prueba en el proceso. Responde a la pregunta sobre qué parte debe aportar prueba al proceso y tiene sus orígenes en el derecho romano, como lo destacan entre otros, Prütting (2010, p. 457) y Carvajal (2014, p. 125).

Sin embargo, no se debe omitir que existen ordenamientos jurídicos como el alemán que carece de una formulación general sobre carga de la prueba, como la del artículo 1698 del Código Civil chileno antes referido. La situación no deja de ser curiosa, pues desde los trabajos de Rosenberg, Leipold, Prütting y otros, se ha construido mayoritariamente para el derecho continental la teoría de la carga de la prueba (Caponi, 2007, p. 283). La teoría de la carga de la prueba nace de este modo desde la doctrina de un sistema jurídico, como el alemán, que carece de una regla legal sobre la carga de la prueba subjetiva.

Luego se habla de la carga objetiva o material de la prueba, que no se dirige a las partes sino al juez y que opera al momento en el que el este forma su juicio. Esta regla solo opera cuando existe una insuficiencia de prueba, de modo tal que el juez no ha podido dar por establecido un determinado hecho. En efecto, si el juez tiene certeza de que los hechos existieron (o no existieron), pues no solo es irrelevante hablar de carga de la prueba en sentido material u objetivo, sino que también lo es determinar quién los probó.

Existiendo la obligación del juez de fallar el asunto sometido a su conocimiento y frente a la opción de tirar los dados u otro método azaroso, la ley opta por esta forma de distribución entre las partes de los riesgos probatorios. De este modo, si no hay claridad sobre un hecho determinado, el juez observará qué parte se ve beneficiada con la comprobación de ese hecho y si esa parte no ha introducido prueba al respecto, fallará en su contra.

Las reglas sobre la carga de la prueba se aplican con posterioridad a la valoración de dichas evidencias. Si el juez no ha logrado dar por establecido el hecho debatido, estas reglas le señalan al juez cómo decidir (Meneses, 2017).

Con el concepto de carga se apunta hacia un imperativo procesal que, de conformidad con Goldschmidt (1936), juega en el propio interés de las partes. Las cargas procesales implican determinados actos procesales que intentan prevenir un perjuicio procesal como lo es una sentencia desfavorable. Con la idea de carga de la prueba, entonces, debemos alejarnos de una idea de deber u obligación.

La carga de la prueba se establece bajo una lógica absolutamente privatista del proceso civil y, desde luego, bajo la inspiración del principio dispositivo (Ricci, 2001). Supone, por lo demás, que entre demandante y demandado no 
existen diferencias que pueden traducirse en asimetrías de información importantes, en capacidad económica para obtener pruebas, etcétera. El onus probandi vigente se construye en un sistema tradicional de igualdad ante la ley, es decir, una igualdad formal.

Como se señalaba, la carga de la prueba en sentido objetivo o regla de juicio, opera solo en caso que un hecho haya quedado incierto o donde haya existido insuficiencia de prueba. En todos esos casos, el juez, obligado que está de fallar, deberá aplicar las reglas de juicio, si es que el legislador las ha contemplado.

Por el contrario, cuando el juez ha adquirido la certeza necesaria sobre los hechos objeto del juicio, no opera la carga de la prueba como regla de juicio. En este caso deja de ser relevante la distinción entre autor y destinatario de la actividad probatoria, puesto que, con independencia de quién haya introducido y practicado la prueba, el órgano jurisdiccional es libre para valorarla, encontrándose sometido exclusivamente al resultado que de ella se derive, sea o no beneficioso para la parte que la propuso.

En otro orden de ideas, si bien las reglas sobre distribución de la carga de la prueba predeterminan la actividad probatoria que deberá realizar cada parte, ellas no son una regla absoluta, de modo tal que la inactividad probatoria de una parte no lleva necesariamente a desestimar su pretensión o resistencia. Es que la carga de la prueba corresponde a aquellas cargas que Goldschmidt (1936) denomina como menos perfectas (p. 100). Una carga procesal es menos perfecta cuando los perjuicios que son las consecuencias de la rebeldía, se producen solo arbitrio iudicis. Esto quiere decir, que la parte que no produce actividad probatoria genera el efecto de poner en peligro la última expectativa de obtener una sentencia favorable. Pero, no se produce necesariamente que quien debía probar un hecho y no lo hizo indefectiblemente perderá el juicio. Es muy probable que quien no aporte los medios de prueba referidos a su interés, no obtenga una sentencia favorable a su posición, pero si el juez u otra parte introducen pruebas, puede perfectamente obtener una sentencia favorable a su necesidad.

Piénsese en la situación no tan infrecuente de la parte que presenta un testigo a declarar en el proceso, pero con su declaración este debido al juez o a la contraparte, declara de un modo perjudicial para los intereses de la parte que lo presenta. En este caso puede ocurrir que una parte no presentó pruebas relativas a su pretensión o interés, pero igualmente puede obtener una sentencia que le beneficia, gracias a la prueba presentada por la otra parte.

Parte de la doctrina es crítica con esta versión objetiva de la carga de la prueba. Acá ya no se trata -se dice- de un reparto de cargas y ni siquiera de una cuestión de cargas, "sino de la simple averiguación de los hechos en el proceso" (Nieva, 2018, p. 12). 
Por otro lado, todo el tema de la carga de la prueba adquiere importancia solo en el caso de que el juez no haya podido dar por establecido un hecho. Acaecido aquello, la ley "establece como consecuencia la derrota de la parte que había invocado ese hecho como fundamento de su demanda o de su excepción" (Taruffo, 2019, p. 17).

Hoy en día, al decir de Ferrer (2019), rige el principio de adquisición procesal o de comunidad de la prueba, que sostiene que una vez que las pruebas se aportan al procedimiento, importa únicamente lo que de ellas se infiera sobre los hechos a probar, con independencia de quién los haya aportado.

Ello es así, como "consecuencia del principio de adquisición procesal, en virtud del cual el resultado de los actos procesales pasa a formar parte del proceso con independencia de quién los realizó, pudiendo beneficiar o perjudicar a cualquiera de las partes" (Fernández López, 2012, p. 177).

Dibujada en sus trazos elementales la carga de la prueba en el proceso civil, se debe señalar, que en las últimas décadas, la regulación de esta se ha hecho cargo de otra manera de la situación de desigualdad probatoria que existe entre las partes de una contienda. En general, las legislaciones procesales civiles contemporáneas han ideado distintas maneras para facilitar la comprobación de los hechos invocados por los sujetos débiles o donde en general existan asimetrías de información relevantes o dificultades para disponer de las pruebas. Es posible observar, de este modo, como ha ido naciendo la preocupación de dejar atrás una igualdad formal entre las partes de un proceso y encaminarse por una igualdad material, donde se atenúen las diferencias económicas o culturales entre las partes (González Coulon, 2013). Es, desde luego, una propuesta política basada en una mejor justicia distributiva y también en un desarrollo del principio de igualdad que consagran la mayoría de las constituciones vigentes de los diferentes Estados.

Se habla de reglas sobre facilidad y disponibilidad probatoria. Las primeras son más amplias que las segundas. El criterio general y tradicional del onus probandi expresado en que corresponde introducir los medios probatorios a quien alega un hecho del que se deriven consecuencias positivas para él, corresponde a una regla de facilidad probatoria. Se entiende por el legislador que se facilita la comprobación de la verdad de lo discutido en el proceso, cuando se grava sobre cada parte que invoca unos hechos que le son favorables introducir los medios de prueba que acreditan esos hechos. Pero, en ocasiones, aunque cada parte está en la situación de probar los hechos que le son favorables según el criterio antes señalado, la parte contraria puede verse con la carga de aportar las pruebas de esos hechos esgrimidos por la contraria, porque ello puede realizarse de un modo más rápido o más fácil (Fernández López, 2012).

Y por disponibilidad probatoria se apunta a que la parte que no ha invocado unos hechos se ve en la situación de aportar los medios probatorios que acreditan 
tales hechos, por tener un acceso material exclusivo a esas pruebas o por ser la única que conoce el dato que hay que incorporar al proceso (Fernández López, 2012, p. 183).

En el caso de que la debilidad de una de las partes sea el motivo para alterar las reglas sobre la carga de la prueba, o bien cuand o no se dispone de las pruebas, las legislaciones echan mano, como lo resume Ormazabal (2011), de una de las siguientes medidas: a) Alterando las reglas relativas a la distribución de la carga probatoria, de modo tal que la incerteza sobre el acaecimiento de los hechos constitutivos de la pretensión perjudique al demandado y no al demandante, tal como resultaría de aplicar la regla ordinaria de distribución de la carga de la prueba. b) Estableciendo presunciones de hechos de culpa o responsabilidad. c) Rebajando o disminuyendo el grado de certeza que la prueba haya de suministrar al juez para tener por fijados los hechos constitutivos de la pretensión, situándolo en un nivel de probabilidad cualificada o preponderante, excluyendo así una idea de plena convicción subjetiva o más allá de toda duda razonable. d) Combinando los mecanismos referidos en las letras a) y c), es decir, dando lugar a la inversión de la carga de la prueba si se aportan indicios que hagan plausible o sugieran la probabilidad de que hayan acontecido los hechos constitutivos en que se basa la pretensión (pp. 61-62).

Analizaré a continuación los principales mecanismos de alteración de las reglas tradicionales sobre la carga de la prueba. Primeramente, la denominada carga dinámica de la prueba. Luego me referiré a algunas regulaciones sobre presunciones, especialmente de culpabilidad o responsabilidad civil. Finalmente, me concentraré en algunas situaciones de alteración de la carga de la prueba cuando se aporten determinados indicios probatorios.

\subsection{La carga dinámica de la prueba}

La carga probatoria dinámica implica poner en cabeza de quien está en mejores condiciones de probar determinados hechos, el peso de hacerlo (Giannini, 2019).

El sistema tiene dos variantes. En un caso, el juez lo comunica con la debida antelación a las partes durante el proceso para que puedan reacomodar sus estrategias defensivas.

Otra modalidad consiste que el juez, al momento de dictar sentencia, atribuye la carga de la prueba a la parte que tenía mayor disponibilidad de aportar ese medio de prueba. Dicho de otro modo, en este último caso el juez construye una presunción que termina por atribuir la carga de la prueba a la otra parte, alterando la regla general del onus probandi. Esta es la situación del derecho italiano, donde los jueces en sus sentencias modifican el sistema de carga de la prueba regulado por el legislador por el artículo 2697 del Código Civil. En este último caso, normal- 
mente la parte no ha podido reacomodar su defensa y en algún sentido la decisión del juez lo sorprende y perjudica.

Para los autores Yáñez-Meza y Castellanos (2016), con relación al derecho colombiano, esos dos momentos en realidad identifican dos instituciones diferentes: si la alteración de la carga de la prueba sucede en la sentencia, entonces se estaría frente a una situación de inversión de la carga de la prueba. Si ello se realiza en una etapa anterior a la sentencia, pues ahí correspondería hablar propiamente de carga dinámica de la prueba. Creo que tienen razón estos autores al realizar esta distinción.

En general, esta alteración de la carga de la prueba no goza de buena recepción por parte de la doctrina. Taruffo (2010) la tilda de excesiva (p. 263). Hernán Corral (2012) en Chile señala que ella trastoca todo el delicado entramado de equilibrios, de pesos y contrapesos, del orden jurídico sobre las pruebas de los hechos y la forma en que las personas desarrollan autónomamente su vida en el ámbito del derecho civil. Por otro lado, señala que con este tipo de estándares es prácticamente imposible evitar decisiones cargadas de subjetividad e incluso de sesgo que terminan por desacreditar a los órganos de la judicatura y atenta contra el derecho de defensa y la imparcialidad de juzgador. Finalmente, agrega este autor que tal regla acentúa la litigación en vez de reducirla (pp.112-113). Este último aspecto señalado por este autor debe entenderse, a mi modo de ver, con la imposibilidad de prever razonablemente cuál será la decisión judicial en determinada materia. Esa incerteza jurídica crea las condiciones para aumentar la litigiosidad.

Palomo (2013), pone el acento en una posible afectación del derecho de defensa de las partes en juicio y, al igual que Hernán Corral, destaca una afectación del valor seguridad jurídica (p. 458).

Nieva (2018), va quizás más allá en sus críticas, pues pone acento en la absoluta inutilidad de esta herramienta, desde que el juez valora los hechos con total prescindencia de quien aporte las pruebas al proceso. En los sistemas de prueba libre, como existen hoy en día en la mayoría de los países, el demandado ya no puede esperar que el demandante no consiga probar su pretensión, sino que tiene que aportar la prueba necesaria para intentar ganar el juicio. Hacer lo contrario sería altamente imprudente, exista o no el criterio de la facilidad probatoria .

Para Ferrer (2019), en una línea similar a la de Nieva, el principal problema de la carga dinámica de la prueba es que sienta sus bases en la dimensión subjetiva de la carga de la prueba y, según este autor y otros, queda más que claro que en la dinámica del proceso, esta dimensión de la carga de la prueba es completamente inútil o prescindible.

Con lo expuesto, se puede observar que hay bastante resistencia por un sector de la doctrina a incorporar en el proceso civil esta carga dinámica de la prueba. 
En mi concepto y asumiendo como propias parte de esas críticas, frente a los inconvenientes que presenta un uso discrecional y eventualmente abusivo de esta potestad por parte del juez, así como una posible afectación del derecho de defensa de las partes y una afectación del valor seguridad jurídica, se hace más aconsejable la utilización de otros instrumentos diferentes a una alteración de la carga de la prueba en los términos de la carga dinámica de la misma, lo que permite, además, acercarse de mejor manera a la verdad.

En este sentido, siguiendo a Ferrer (2019), si una de las partes dispone de una prueba relevante o tiene mayor facilidad para producirla, ello parece una buena razón para imponerle el deber de que la aporte al proceso, pero no se ve conveniente ni necesario asignarle el riesgo de perder el proceso por insuficiencia probatoria. Por otra parte, señala este mismo autor, que es fácil imaginar situaciones en que, respecto de un mismo hecho, esté repartida entre las partes la disponibilidad de las pruebas relevantes. En esa situación, modificar la asignación de la carga de la prueba objetiva tendría un efecto sobre los relativos incentivos para una u otra de las partes, pero en ningún caso permitiría incentivar a ambas partes por igual para que aporten las pruebas de que disponen. En este sentido, epistemológicamente, la carga de la prueba dinámica no es un buen mecanismo.

Mejor que introducir una regulación de la carga dinámica de la prueba, es dar al juez poderes oficiosos de prueba y, también, obligar a las partes a exhibir documentos. Esta obligación de exhibir documentos queda mejor conceptualizada si se entiende como un deber de las partes en el proceso, de colaboración o de otro tipo, que tiene como referente al Estado. Por ello, si la parte no colabora, la consecuencia debe ser una sanción, normalmente una multa a beneficio fiscal. Tampoco debe descartarse el arresto o la condena en costas del juicio a esa parte rebelde (Bordalí, 2016a).

El pago de una multa desde luego no va a intimidar siempre a litigantes pudientes o poderosos, pero puede pensarse en un rango progresivo de valores como multa y aplicar el máximo de ese rango a sujetos con suficiente capacidad económica. Pagada o no la multa, si persiste la no rendición de la prueba solicitada, se debe proceder al arresto de la parte rebelde.

Señalado lo anterior, se debe expresar que una situación diversa a la carga probatoria dinámica, se da con ocasión de aquellos casos difíciles de probar para el demandante común. Piénsese en aquellos procesos en que se demanda la reparación del medio ambiente o una indemnización de perjuicios derivada de daños al ambiente. En estos casos, a veces, el legislador, a priori, pone en cabeza del sujeto demandado la carga de la prueba.

Como expresa Denti (1982), es difícil pensar que las normales técnicas probatorias y el mismo instituto de la carga de la prueba puedan encontrar aplicación en la tutela jurisdiccional de los intereses difusos, sin que ello derive en un sustancial 
vaciamiento de las posibilidades de tutela. Dificultades de este género -expresa el mismo autor-, habrían inducido al legislador estadounidense, en la National Environmental Policy Act de 1969, a imponer una suerte de inversión de la carga de la prueba, obligando a los órganos administrativos establecidos para la tutela del ambiente a justificar su proceder ( 227 y ss.). En este caso, si una persona demanda a dicha administración por daño al ambiente, será la misma administración quien tendrá que probar que la actividad autorizada no tiene efectos dañinos para el ambiente y que, además, no existían otras alternativas practicables.

Si bien en el caso anterior estamos en un proceso de indemnización contra la administración del Estado, ese proceso de responsabilidad extracontractual conserva en sus trazos principales las particularidades de un proceso civil1.

Sin embargo, en este caso se está ante una situación bastante diversa de la carga dinámica de la prueba, pues se trata de una inversión prevista por la ley con un carácter general y, por lo mismo, con anterioridad a todo proceso en que deba regir. Se trata más bien, se ha dicho, de normas de carácter sustantivo cuya consagración tiene por finalidad despejar dudas interpretativas de las normas comunes de la carga de la prueba o para establecer una repartición más equitativa de las cargas procesales (Hunter, 2015, pp. 225-226).

En este último caso, todas las críticas que se formulan a la carga dinámica en el sentido de alteración de las estrategias defensivas de las partes y por acentuar la discrecionalidad judicial, desaparecen. En esta situación, la alteración de la carga de la prueba ya está definida a priori en la ley y es igual para todos los casos. No existe afectación del derecho de defensa del sujeto demandado, pues no hay sorpresas de ningún tipo durante la realización del proceso. Por otra parte, los sujetos saben con antelación a qué sujetarse en caso de que deban comparecer en un proceso judicial, por lo que se produce mayor seguridad jurídica.

\subsection{Presunciones de hechos, culpabilidad o responsabilidad}

Las presunciones legales son consideradas por un sector de la doctrina dentro de la tipología de herramientas de facilidad probatoria (Hunter, 2015). Esta misma doctrina distingue entre presunciones legales propiamente tales y las verdades provisionales o interinas. En las primeras, el legislador tipifica ciertos supuestos fácticos probados, en los cuales se da por establecido otro hecho determinado también por el legislador y que integra el supuesto fáctico que permite obtener

1 Se debe destacar que aún en un proceso contencioso administrativo de nulidad, la carga de la prueba aparece regulada de un modo muy parecido a la de un proceso civil. Hoy en día se ha entendido que la presunción de validez del acto administrativo, prácticamente no tiene ninguna mayor implicancia para el tema de la carga de la prueba, conservando en sus trazos principales la misma regla tradicional del proceso civil. Un análisis sobre este aspecto puede verse en Bordalí (2016b) p. 202. 
la consecuencia jurídica. En cambio, con las verdades interinas, se produce una exención probatoria por el solo ministerio de la ley, desde que el legislador ha dado por cierto un hecho sin necesidad de prueba. En este caso, el sujeto perjudicado por la verdad interina, tendrá el peso de probar que la verdad predeterminada por el legislador no ha ocurrido (Hunter, 2015).

Taruffo (2010) critica este sistema de presunciones por cuanto, pese a ser justas o políticamente adecuadas, no parecen buscar precisamente la verdad (p. 260), y por ello no deben ser admitidas sin más.

Este tipo de técnica, que facilita la prueba, generalmente se utiliza para probar situaciones fácticas referidas al dolo, la buena fe, la culpa, entre otras. Piénsese en una demanda de reparación o de indemnización por daños al medio ambiente, donde es muy difícil acreditar el dolo y la relación de causalidad entre el dolo y el daño. Acá no se invierte totalmente la carga de la prueba por medio de la ley como en la National Environmental Policy Act, sino que se establece una presunción a favor de la parte demandante.

El legislador chileno ha avanzado por este tipo de reglas en materia de juicios de responsabilidad civil por daño ambiental. Así, el artículo 52 de la Ley de Bases del Medio Ambiente (Ley n.ํㅜ 19.300), prescribe una presunción de culpabilidad para el que cause daño ambiental y no diere cumplimiento a las normas de calidad ambiental, a las normas de emisiones, a los planes de prevención o de descontaminación, a las regulaciones especiales para los casos de emergencia ambiental o a las normas sobre protección, preservación o conservación ambientales, establecidas en la Ley 19.300 o en otras disposiciones legales.

El precepto de la ley chilena (art. 52 de la Ley n. $\underline{0}$ 19.300) establece una presunción de culpa -aunque la ley hable de presunción de responsabilidad- del autor del daño ambiental, en el caso que este haya infringido las normativas que dicho artículo expresa. En este caso, la culpa en el daño ambiental se presume, por lo que corresponderá al sujeto que causa el daño y no al actor probar que ha actuado con diligencia. Pinilla (2019) define a esta situación como una alteración de carga de la prueba para el caso de la culpa infraccional.

La presunción comentada admite, desde luego, prueba en contrario, pero si no se introduce esta y se prueba por el actor la infracción, el daño y el nexo causal, el sujeto demandado será condenado a la reparación del daño ambiental. Será de cargo del sujeto demandado, por lo tanto, probar que ha operado con la debida diligencia o cuidado.

Se trata de una presunción que tiene por fin facilitar la actividad probatoria de la parte demandante y constituye una especie de incentivo o castigo, según como se le mire, en relación con el cumplimiento o no de la normativa de carácter ambiental. Ahora bien, ello no implica que el demandante de daño ambiental esté 
exonerado de prueba, pues le corresponderá siempre probar la infracción de la normativa, el daño producido y el nexo causal entre la acción del demandado y el daño producido.

En este caso, la ilegalidad en la conducta del demandado no es requisito de la responsabilidad, sino que es solo presupuesto de una presunción iuris tantum de culpabilidad, que admite actividad probatoria en contrario. Por lo tanto, aun cuando no se cumpla con la ley, es perfectamente posible que el agente que causa el daño pueda en definitiva exonerarse de la responsabilidad, para lo cual debe probar que ha actuado con la debida diligencia y cuidado en la situación concreta.

Este tipo de presunción que emplea el legislador ambiental chileno es definido como de culpa subjetiva atenuada (Saavedra, 2011, p. 154), lo que permite a quien es demandado y no ha dado cumplimiento a la normativa ambiental exigible, introducir pruebas en el juicio para demostrar que ha cumplido con el deber general de no causar daño y descartar la culpabilidad. Por otra parte, no hay razones ni de texto ni de equidad para descartar la situación inversa, esto es, probar que quien ha dado cumplimiento a la normativa, ha obrado, sin embargo, con culpa (Hunter, 2005).

Haciendo una valoración de este tipo de presunciones, creo que ellas sacrifican muy gravemente una justicia basada en la verdad de los hechos de la controversia. Por lo tanto, no soy partidario de su introducción.

\subsection{Inversión de la carga de la prueba frente a indicios}

El derecho laboral es el espacio más claro fuera del derecho público que genera relaciones jurídicas desiguales o donde se configura una asimetría significativa entre las partes (González Coulon, 2013, p. 161). Configurar la relación laboral entre empleador y trabajador como una relación jurídica entre sujetos que se vinculan en términos de igualdad, es algo absolutamente irreal. Desde hace más de un siglo que se asume que la relación laboral es desigual y como tal, necesita de una activa regulación protectora por parte del Estado. Y ese rol protector del Estado en favor del trabajador se traspasa también al ámbito del proceso laboral.

El proceso laboral está informado por algunos principios que intentan fortalecer, en casos interpretativamente dudosos, la posición del trabajador. Asimismo, la ley suele contemplar instituciones y reglas que derechamente benefician la posición del trabajador. Se trata, entre otros, de los principios de protección y pro operario.

Sin embargo, estoy de acuerdo con Meneses (2017) cuando sostiene que los principios de protección y pro operario no pueden ser considerados en la tarea de valorar las pruebas según la sana crítica, ya que estas máximas intervienen en 
el campo de la interpretación y aplicación del derecho laboral y no en el establecimiento de los hechos.

Sin embargo, la legislación procesal laboral no ha estado ausente en reglas que intentan facilitar la prueba de los trabajadores que demandan a sus empleadores. Una de las herramientas que utilizan algunas legislaciones en materia de proceso laboral, es la inversión de la carga de la prueba o la atenuación del clásico onus probandi mediante la incorporación de indicios.

Así, por ejemplo, el legislador laboral chileno creó hace ya unos años (2006) un procedimiento especial para la tutela de los derechos fundamentales de los trabajadores. Este procedimiento contiene una serie de disposiciones que facilitan el acceso a la justicia de los trabajadores afectados en sus derechos fundamentales, así como la rendición de las pruebas.

En relación al tema probatorio, el legislador chileno dispuso una norma sobre facilidad probatoria que beneficia al trabajador denunciante. Dispone al efecto el artículo 493 del Código del Trabajo que "cuando de los antecedentes aportados por la parte denunciante resulten indicios suficientes de que se ha producido la vulneración de derechos fundamentales, corresponderá al denunciado explicar los fundamentos de las medidas adoptadas y de su proporcionalidad".

Esta es una típica herramienta usada en el derecho estadounidense y europeo en las normativas antidiscriminatorias. Se trata de una alternativa que mezcla la vía de alterar las reglas sobre la carga de la prueba con una disminución en el grado de certeza que la prueba le arroja al juez para dar por establecidos los hechos constitutivos de la pretensión.

En el proceso de tutela de derechos fundamentales de los trabajadores del derecho chileno, se utiliza la técnica de facilidad probatoria para el trabajador demandante, considerando las dos situaciones en que se encuentra dicho sujeto. En primer lugar, en atención a que la infracción de aquellos derechos por parte del empleador suele ser sutil, a través de conductas no manifiestamente ni directamente atentatorias contra los mismos. Por otra parte, debido a que es el empleador y no el trabajador el que suele tener cierto control sobre las fuentes probatorias que pueden introducirse al proceso 2 .

De este modo, es común que los empleadores ejerzan cierta presión sobre otros trabajadores de la misma unidad empresarial o lugar de trabajo del demandante para que no declaren en su contra en el juicio. En algunos casos ni siquiera

2 Entiendo por fuente de prueba, siguiendo a Meneses, como algo distinto a medio de prueba. La diferencia esencial está dada porque la fuente probatoria tiene una ubicación previa y extraña al juicio, mientras que los medios de prueba entran derechamente en la dinámica procesal, los que son utilizados por las partes como base de su argumentación en el proceso y por el tribunal para justificar la determinación de la cuestión fáctica (Meneses, 2008, p. 63). 
es necesario ejercer presión alguna, sino que los trabajadores que han presenciado algunas conductas indebidas por parte del empleador, se niegan a declarar en juicio para salvaguardar así sus puestos de trabajo.

Por otra parte, si en el lugar de trabajo existen cámaras de vigilancia u otros medios de registro visual o sonoro, es el empleador quien dispone de las grabaciones de las cámaras o de los registros, pudiendo, si es necesario, destruirlos u ocultarlos. Todo ello conspira contra las posibilidades de obtener pruebas por parte de los trabajadores.

Constatando este tipo de dificultades probatorias, a nivel del derecho comunitario europeo, se promulgó la Directiva 2000778/CE, del 27 de noviembre de 2000 , relativa al establecimiento de un marco general para la igualdad de trato en el empleo y la ocupación. En ella se señala:

1. Los Estados miembros adoptarán, con arreglo a su ordenamiento jurídico nacional, las medidas necesarias para garantizar que corresponda a la parte demandada demostrar que no ha habido vulneración del principio de igualdad de trato, cuando una persona que se considere perjudicada por la no aplicación, en lo que a ella se refiere, de dicho principio alegue, ante un tribunal u otro órgano competente, hechos que permitan presumir la existencia de discriminación directa o indirecta.

2. Lo dispuesto en el apartado 1 se entenderá sin perjuicio de que los Estados miembros adopten normas sobre la prueba más favorables a la parte demandante.

3. Lo dispuesto en el aparatado 1 no se aplicará a los procedimientos penales.

4. Lo dispuesto en los apartados 1,2 , y 3 se aplicarán asimismo a toda acción judicial emprendida de conformidad con el apartado 2 del art. 9.

5. Los Estados miembros no estarán obligados a aplicar lo dispuesto en el apartado 1 a los procedimientos en los que la instrucción de los hechos relativos al caso corresponda a los órganos jurisdiccionales o a otro órgano competente ${ }^{3}$.

No basta en estos casos una mera alegación de trato discriminatorio o desigual para que se traslade a la parte demandada el peso de la prueba, sino que se requiere algo más. Ese algo más camina por una idea de demostración o acreditación (Ormazabal, 2011, p. 82).

El sentido de esas disposiciones europeas, siguiendo a Ormazabal (2011), avanza por una idea de que si el actor logra acreditar indiciariamente (sin plena

3 Antes de dicha normativa, existía una anterior similar, del año 1997 (Directiva 97/80). 
certeza, mediante un principio de prueba) los hechos constitutivos fundantes de la discriminación, el demandado queda gravado con la carga de aportar plena certeza en relación con su no acaecimiento y, de no lograrlo, sucumbiría en el proceso.

En este caso, se pone del parte del empleador la carga de la prueba si es que el demandante aporta algún elemento probatorio, aunque mínimo, de modo tal que haga plausible, sugiera o indique, la probabilidad de que el empleador vulneró algún derecho fundamental del trabajador. Corresponderá entonces en este caso al empleador aportar pruebas que puedan demostrar que las medidas que adoptó respecto del trabajador son justificadas y razonables, de manera tal que no constituyen una violación de sus derechos fundamentales.

Hay que destacar que no se está en una situación pura y dura de inversión de la carga de la prueba, pues no basta que el trabajador invoque en su denuncia que se le vulneró un derecho fundamental para que, de esa manera, le corresponda íntegramente el peso de la prueba al demandado en orden a desvirtuar tal aseveración. Más que inversión de la carga de la prueba, estamos frente a casos de disponibilidad de la prueba, aligeramiento de la carga de la prueba o desviación de la carga de la prueba (Guidotti, 2013, p. 158).

\begin{abstract}
Se trataría, en definitiva, de una reducción del grado o estándar de certeza normalmente exigible a la prueba (lo que en Alemania se denomina Beweismassreduzierung). En vez de la certeza moral excluyente de dudas razonables entraría en juego el paradigma de la probabilidad preponderante (Überwiegende Wahrscheinlichkeit), un resultar más probable la producción del hecho que su no producción. (Ormazabal, 2011, p. 85)
\end{abstract}

Al trabajador se le exige una mínima carga de aportar antecedentes probatorios que sugieran que se ha producido la vulneración de sus derechos fundamentales. Se exige aportar antecedentes y no bastan las meras alegaciones por parte del trabajador (Santibáñez, 2010). Introducidos esos antecedentes probatorios, aunque sean mínimos, ello no se traduce en que se deban dar por establecidos los hechos señalados por el actor, sino que hace operar una inversión de la carga de la prueba en perjuicio del demandado, quien deberá probar que no realizó una conducta ilegítima que vulneró un o algunos derechos fundamentales del actor.

Se trata de una clara normativa de facilidad probatoria o de aligeramiento probatorio que tiene una doble justificación: por una parte, la posición de sujeto más débil del trabajador frente al empleador y, por otra, un interés por parte del Estado en orden a que los derechos fundamentales de los trabajadores al interior de la empresa sean íntegramente respetados. 
Preceptos como el artículo 493 del Código del Trabajo chileno, traen como consecuencia que, aportados indicios por parte del trabajador demandante de que le han sido vulnerados sus derechos fundamentales durante la vigencia de la relación laboral o con ocasión del término de esta, si el tribunal no logra tener certeza sobre los hechos denunciados, el costo del hecho incierto o dudoso recae sobre el empleador demandado (Ugarte, 2009).

Hay que tener presente que, si el trabajador demandante logra introducir prueba la directa que acredite que sufrió una vulneración de sus derechos fundamentales por hechos imputables al empleador, el tribunal, sin necesidad de aplicar ninguna regla sobre la carga de la prueba, acogerá la demanda. Por su parte, si el demandado introduce prueba suficiente al proceso que demuestre su actuar legítimo coherente con la plena vigencia de los derechos fundamentales del trabajador, el tribunal deberá desechar la demanda sin necesidad, tampoco, de aplicar reglas sobre la carga de la prueba.

Lo curioso es que frente a la normativa europea donde se traslada al demandado el demostrar que no ha existido un trato desigual o discriminatorio, la normativa chilena solo hace referencia a que el demandado tiene el peso de explicar los fundamentos de las medidas adoptadas y de su proporcionalidad (art. 493 Código del Trabajo). En el caso europeo se sitúa el tema en la prueba (demostrar) y en la situación chilena en la alegación o defensa (explicar). Sin embargo, la doctrina (Santibáñez, 2010, p. 90; Ugarte, 2009, p. 225;) y algunos fallos de Cortes chilenas (Corte de Apelaciones de Puerto Montt, Sentencia 82, 2010; Corte de Apelaciones de Rancagua, Sentencia 102, 2010), lo han interpretado en el sentido de acreditar, demostrar o probar.

La regla parece presentar cierta utilidad respecto al trabajador que deman$\mathrm{da}$, pues introducidos los medios probatorios para configurar los indicios, hace surgir en cabeza del empleador demandado una carga extra en relación con los términos del debate, pues deberá demostrar la racionalidad de los fundamentos de las medidas adoptadas y de su proporcionalidad. Al configurarse los indicios, al empleador demandado no le bastará demostrar que no afectó los derechos fundamentales del empleador, sino que tiene que demostrar que las medidas que adoptó son racionales y proporcionales. En algún sentido los indicios hacen aumentar la carga argumentativa del empleador, lo que puede favorecer la posición del trabajador.

En definitiva, si bien este tipo de reglas pueden afectar en parte el valor verdad como objetivo del proceso, su fin de justicia y de defensa de los derechos fundamentales de los trabajadores, hace que esa eventual merma del valor verdad aparezca razonable y adecuada. 


\section{Conclusiones}

a. La evolución del proceso civil desde fines del siglo XIX en adelante, ha avanzado al considerar la posición material de las partes de la relación jurídica procesal. En este sentido, desde esta época en adelante los legisladores de muchos países han regulado el estatuto del juez y el proceso judicial de un modo tal que se asegure que las partes no solo sean formalmente iguales ante la ley, sino también materialmente. La posición desigual del sujeto pobre o, generalmente, débil, es compensada, en un primer momento, con un juez con mayores poderes y con un abogado gratuito que lo representa en juicio.

b. El reparto del trabajo de introducir las pruebas en el proceso desde comienzos del siglo XIX y casi todo el siglo XX, se basaba en la idea de que quien alegaba hechos que beneficiaban su posición, tenía la carga de introducir las pruebas de esos hechos. En ese caso, si al momento de fallar el juez no tenía claridad sobre por qué el hecho no resultó probado, gravaba con el riesgo de esa incerteza a la parte que debiendo introducir pruebas, no lo hizo.

c. A fines del siglo XX, los legisladores de muchos países de tradición jurídica continental, observaron que muchas veces las partes no podían introducir las pruebas para dar por acreditada su pretensión, bien porque no tenían el dinero o capacidad para introducir esas pruebas o bien, porque no tenían acceso o disponibilidad de esas pruebas. Avanzando aún más en la idea de obtener una igualdad material entre las partes, comienzan a regularse reglas sobre facilidad o disponibilidad probatoria.

d. Una de las reglas sobre facilidad probatoria más conocidas es la carga dinámica de la prueba. Esta regla tiene dos variantes. Una, como en Italia, en que el juez al momento de dictar sentencia, puede alterar la regla de la carga de la prueba para favorecer así la posición de aquella parte que no tuvo facilidad a la prueba. Es criticable esta regla porque afecta claramente el derecho de defensa de las partes y crea inseguridad jurídica. La otra variante consiste en que el juez en el trámite del proceso, avisa a las partes que alterará la carga de la prueba para favorecer así a quien observa como la parte débil o con dificultades para obtener medios de prueba favorables a su posición. En este caso, ya no hay una evidente afectación del derecho de defensa y tampoco una radical afectación del valor seguridad jurídica. Sin embargo, en sus dos variantes, se debe señalar que ellas, además de mostrarse algo inútiles en la práctica por la idea de comunidad de prueba que rige en el proceso, no contribuyen mayormente al descubrimiento de la verdad que es el objetivo que debe buscar todo proceso. 
e. En razón de las críticas antes señaladas, se ve más aconsejable mantener y fortalecer los poderes probatorios oficiosos del juez. Y junto con ello, establecer deberes de colaboración de las partes en materia de prueba, siendo un deber de la parte que tiene una determinada prueba o acceso a ella, introducirla, so pena de ser sancionado si no cumple con lo ordenado. Estas reglas permiten favorecer de mejor modo a la parte que no tiene acceso a una determinada prueba y logran de mejor modo que se imparta justicia con base en la verdad de los hechos discutidos en la causa.

f. Otros instrumentos de facilidad probatoria son las presunciones sobre hechos, responsabilidad o culpa. Se trata de presunciones iuris tantum que admiten prueba en contrario. Estas no siempre han demostrado ser particularmente eficaces para facilitar la introducción de las pruebas en favor de los sujetos demandantes. Tampoco contribuyen a obtener una justicia basada en la verdad de los hechos discutidos en el proceso. Su contribución es muy marginal.

g. Finalmente, otra regla de facilidad probatoria analizada, es aquella en que si el actor logra acreditar indiciariamente (sin plena certeza, mediante un principio de prueba) los hechos constitutivos fundantes de su demanda, es el demandado quien queda gravado con la carga de aportar plena certeza en relación con su no acaecimiento, y de no lograrlo sucumbiría en el proceso. Un caso de uso de este tipo de reglas es el proceso de tutela de derechos fundamentales del trabajador del derecho chileno. La regla parece presentar cierta utilidad respecto al trabajador que demanda, pues introducidos los medios probatorios para configurar los indicios, hace surgir en cabeza del empleador demandado una carga extra en relación con los términos del debate, pues deberá demostrar la racionalidad de los fundamentos de las medidas adoptadas y de su proporcionalidad. Al configurarse los indicios, al empleador demandado no le bastará demostrar que no afectó los derechos fundamentales del empleador, sino que tiene que demostrar que las medidas que adoptó son racionales y proporcionales. En algún sentido los indicios hacen aumentar la carga argumentativa del empleador, lo que puede favorecer la posición del trabajador.

\section{Referencias bibliográficas}

Bordalí, A. (2016a). Nuevas herramientas probatorias en el proceso civil chileno. Análisis en un contexto de facilidad probatoria. Revista de Derecho, 23(1), 173-198.

Bordalí, A. (2016b). La carga y valoración de la prueba en el contencioso de reclamación ante los tribunales ambientales. En Arancibia, J. y Romero Seguel, A. (coords.), 
La prueba en la litigación pública (pp. 193-210). Santiago de Chile: Universidad de Los Andes, Librotecnia.

Caponi, R. (2007). Note in tema di poteri probatori delle parti e del giudice del processo civile tedesco dopo la reforma del 2001. En AA.VV (comps.), Atti del Convegno Nazionale. Cagliari, 7 - 8 ottobre 2005. (pp. 265- 301). Milán: Giuffrè.

Cappelletti, M. y Garth, B. (1996). El acceso a la justicia. La tendencia en el movimiento mundial para hacer efectivos los derechos. México: Fondo de Cultura Económica.

Carvajal, P. I. (2014). Onus probandi: la formación del artículo 1.698 del Código Civil de Chile. Fundamina, 20(1), 125-133.

Cipriani, F. (1997). Ideologie e modelli del processo civile. Nápoles: Edizioni Scientifiche Italiane.

Corral, H. (2012). Sobre la carga de la prueba en el Proyecto de Código Procesal Civil. En Aguirrezábal, M. (ed.), Justicia civil: perspectivas para una reforma en la legislación chilena, (pp. 107-117). Santiago de Chile: Universidad de los Andes.

Chile. Corte de Apelaciones de Puerto Montt. Sentencia 82. (2010).

Chile. Corte de Apelaciones de Rancagua. Sentencia 102. (2010).

Damaska, M. (2000). Las caras de la justicia y del poder del Estado. Análisis comparado del proceso legal. Santiago: Editorial Jurídica de Chile.

Denti, V. (1982). Un progetto per la giustizia civile. Bolonia: Il Mulino.

Fernández López, M. (2012). El juez civil y el hecho incierto. Un estudio desde la perspectiva de los principios de facilidad y disponibilidad probatoria. Derecho y sociedad, 38, 176-184.

Ferrer, J. (2019). La carga dinámica de la prueba. Entre la confusión y lo innecesario. En Nieva, J., Ferrer, J. y Giannini, L. (dirs.), Contra la carga de la prueba (pp. 53-87). Madrid: Marcial Pons.

Giannini, L. (2019). Revisitando la doctrina de la 'carga de la prueba`. Aportes para esclarecer sus principales problemas conceptuales. En Nieva, J., Ferrer, J. y Giannini, L. (dirs.), Contra la carga de la prueba (pp. 89-115). Madrid: Marcial Pons.

Goldschmidt, J. (1936). Teoría general del proceso. Barcelona: Editorial Labor.

González Coulon, M. A. (2013). La carga dinámica de la prueba y sus límites. Santiago de Chile: Legal Publishing, Thomson Reuters.

Guidotti, B. (2013). La igualdad y el principio protector en el proceso laboral. En Muñoz, F. (ed.), Igualdad, inclusión y derecho. Lo político, lo social y lo jurídico en clave igualitaria (pp. 153-164). Santiago de Chile: Lom.

Hunter, I. (2005). La culpa con la ley en la responsabilidad civil ambiental. Revista de Derecho, 18(2) 9-25. DOI: 10.4067/50718-0950200500200001

Hunter, I. (2015). Las dificultades probatorias en el proceso civil. Tratamiento doctrinal y jurisprudencial, críticas y una propuesta. Revista de Derecho, 22(1), 209-257. 
Meneses, C. (2008). Fuentes de prueba y medios de prueba en el proceso civil. Ius et Praxis, 14(2), 43-86.

Meneses, C. (2017). Estudios sobre el proceso civil chileno. Valparaíso: Prolibros.

Nieva, J. (2018). La carga de la prueba: una reliquia histórica que debiera ser abolida. Revista ítalo-española de Derecho Procesal, 1, 1-17.

Ormazabal, G. (2011). Discriminación y carga de la prueba en el proceso civil. Madrid: Marcial Pons.

Palomo, D. (2013). Las cargas probatorias dinámicas: ¿es indispensable darse toda la vuelta?. Ius et Praxis, 19(2), 447-464.

Pinilla, F. (2019). Daño ambiental y Administración: su función y determinación en el sistema sancionatorio ambiental. En Ferrada, J. C., Bordalí, A. y Prieto, M. (coords), La justicia ambiental ante la jurisprudencia. Actas de las II Jornadas de Justicia Ambiental (pp. 273 - 305). Santiago de Chile: Der ediciones.

Prütting, H. (2010). Carga de la prueba y estándar probatorio: la influencia de Leo Rosenberg y Karl Heinz Schwab para el desarrollo del moderno derecho probatorio. Ius et Praxis, 16(1), 453-463.

Ricci, G. F. (2001). Principi di diritto processuale generale. Turín: Giappichelli.

Saavedra, R. (2011). La doctrina de la Excma. Corte Suprema en materia de responsabilidad ambiental en la experiencia del Consejo de Defensa del Estado. Revista de Derecho, 26, 151-174.

Santibáñez, C. (2010). Las cargas probatorias dinámicas. Revista Chilena de Derecho del Trabajo y de la Seguridad Social, 1(1), 83-92.

Tarello, G. (1989). Dottrine del processo civile. Studi storici sulla formazione del diritto processuale civile. Bolonia: Il Mulino.

Taruffo, M. (2010). Simplemente la verdad. El juez y la construcción de los hechos. Madrid: Marcial Pons.

Taruffo, M. (2019). Casi una introducción. En Nieva, J., Ferrer, J. y Giannini, L. (dirs.), Contra la carga de la prueba (pp. 11-21). Madrid: Marcial Pons.

Ugarte, J. L. (2009). Tutela laboral de derechos fundamentales y carga de la prueba. Revista de Derecho, 33(2), 215-228.

Yáñez-Meza, D. y Castellanos, J. (2016). El derecho a la prueba en Colombia: aspectos favorables y críticos de la reforma del Código General del Proceso en el derecho sustancial y procesal. Universitas, 132, 561-609. 